\title{
4. ADVANCES IN THE MOTOR-DRIVEN CORE BARREL (MDCB) ${ }^{1}$
}

\author{
Scott P. McGrath ${ }^{2}$ and Eigo Miyazaki ${ }^{3}$
}

\section{INTRODUCTION}

The motor-driven core barrel (MDCB) is a prototype coring system developed by the Ocean Drilling Program (ODP). The MDCB is designed for complete compatibility with the bottom-hole assembly (BHA) used by the already operational advanced hydraulic piston corer (APC) and the extended core barrel (XCB) systems. The purpose of the MDCB is threefold. The first is to allow single bit APC/ $\mathrm{XCB}$ holes to be extended to greater depths and into more indurated formations, particularly into fractured crystalline basement rocks. The second is to improve recovery in difficult to recover formations that include such hard/soft interbeds as soft chalks laced with chert stringers. A third objective of the MDCB is to use modern mining technology to core hard, fractured, crystalline rock, massive sulfides, and/or shallow-water reef complexes commonly found on atolls. This technology entails drilling/coring relatively small diameter holes at high bit speeds and light bit weights using narrow kerf diamond core bits. The mining industry has used this technique successfully to core deeply into hard, highly fractured formations with virtually $100 \%$ recovery. To apply this technology to ODP's scientific coring operations, a means of accurately controlling the weight on the small diamond core bit, while coring from a floating vessel, is required.

The MDCB is freefall deployed and retrieved by a sandline. With advance planning and the addition of two drill collar subs into the coring BHA initially, the MDCB can be used at any point during normal APC/XCB coring operations. It is fully interchangeable with the APC and XCB, thus allowing the choice of coring system to be optimized from the mud line down into indurated formations and/or basement rocks. The MDCB advances into the formation ahead of the stationary main roller cone bit and recovers a nominal $57 \mathrm{~mm}(2.25$ in.) diameter core, $4.5 \mathrm{~m}$ (14.76 ft) long in an optional plastic polycarbonate liner, or without a liner if fractured hard rocks are anticipated.

The MDCB is comprised of four main components or subassemblies: a thruster unit for hydraulically applying weight on bit (WOB); a small (95 mm [3.75 in.] outside diameter [O.D.]), positive displacement mud motor for generating downhole rotation and torque; a nonrotating inner tube for receiving the core; and a $95 \mathrm{~mm}$ ( $3.75 \mathrm{in}$.) O.D. narrow kerf diamond bit to cut the core. Figure 1 shows a schematic diagram of the MDCB. The subassemblies of the MDCB are described in more detail below.

\section{MDCB SUBASSEMBLIES}

\section{Thruster Unit}

The thruster unit is comprised of several components that perform a variety of functions. The principal task is to translate hydraulic

'Humphris, S.E., Herzig, P.M.. Miller, D.J., et al,, 1996. Proc. ODP. Init. Repts., 158: College Station, TX (Ocean Drilling Program).

ZOcean Drilling Program, 1000 Discovery Drive, College Station, TX 77844-9547. U.S.A. scott_mcgrath@odp.tamu.edu

3Japan Marine Science and Technology Center, 2-15 Natsushima-Cho, Yokosuka 237, Japan. miyazakie@mstkid.jamstec.go.jp force into mechanical weight on bit (WOB). The pressure drop by circulation through a nozzle sub at the top of the thruster assembly results in downward WOB forces applied to the diamond bit. Interchangeable nozzles allow optimization of the desired WOB at various flow rates. The reaction torque generated by mudmotor rotation as it cuts into the formation is transferred through the kelly to the BHA by way of an XCB latch on top of the mudmotor. The circulating fluid (seawater) is channeled selectively through the mudmotor, into and through the thruster, and to the outlet ports at the face of the main roller cone bit. A small, secondary flow bypasses the mudmotor and is channeled directly to the face of the diamond core bit. This split flow system provides a crucial, negative feedback hydraulic system to operate the MDCB correctly without human intervention despite the changes in formation that are encountered, which call for quick alterations in coring parameters (e.g., WOB and flow). When the diamond core bit cuts into hard-to-core, high-torque material, it draws extra torque from the mudmotor by way of a greater pressure drop through the motor. This slightly reduces the flow to the thruster mechanism, which in turn causes an instantaneous reduction of WOB. At the same time, flow to the diamond bit is automatically increased for greater cooling effect and more efficient removal of cuttings.

The stroking portion of the tool (hexagonal male kelly, core barrel, and diamond core bit) is maintained in a latched position until after the tool has landed in the BHA and 500 psi of pressure is reached. After this point, the flow rate is increased to 190 gpm to operate the mudmotor and initiate coring. The thruster assembly includes a damping chamber to inhibit the core barrel from lunging when it first releases from the latch or when breaking through alternating hard/ soft layers while coring. After advancing into the formation and cutting the core, the stroking assembly hydraulically signals the end of stroke to the driller on deck.

\section{Positive Displacement Motor}

The MDCB is powered by an Eastman Christensen (EC) positive displacement mudmotor. The mudmotor has the following operating parameters:

$\begin{array}{lr}\text { Tool size (inch, O.D.) } & 3.75 \\ \text { Lobes (rotor/stator) } & 7 / 8 \\ \text { Pump rate (gpm) } & 190 \\ \text { Bit speed (rpm) } & 410 \\ \text { Maximum torque (ft-lb) } & 1250 \\ \quad \text { Efficiency } & >90 \% \\ \text { Motor pressure (psi) } & 1160 \\ \text { Power (hp) } & 96\end{array}$

\section{Core Barrel Assembly}

The core barrel assembly used with the MDCB is a modified version of a standard Christensen Mining Products (CMP) HWD4 core barrel. The barrel contains a nonrotating inner tube that may be run with or without a polycarbonate liner. The core is retained using either a standard slip-type core catcher installed in a inner tube shoe (for hard formations) or a special spring-loaded, dog-type core-catcher shoe (for soft formations). 


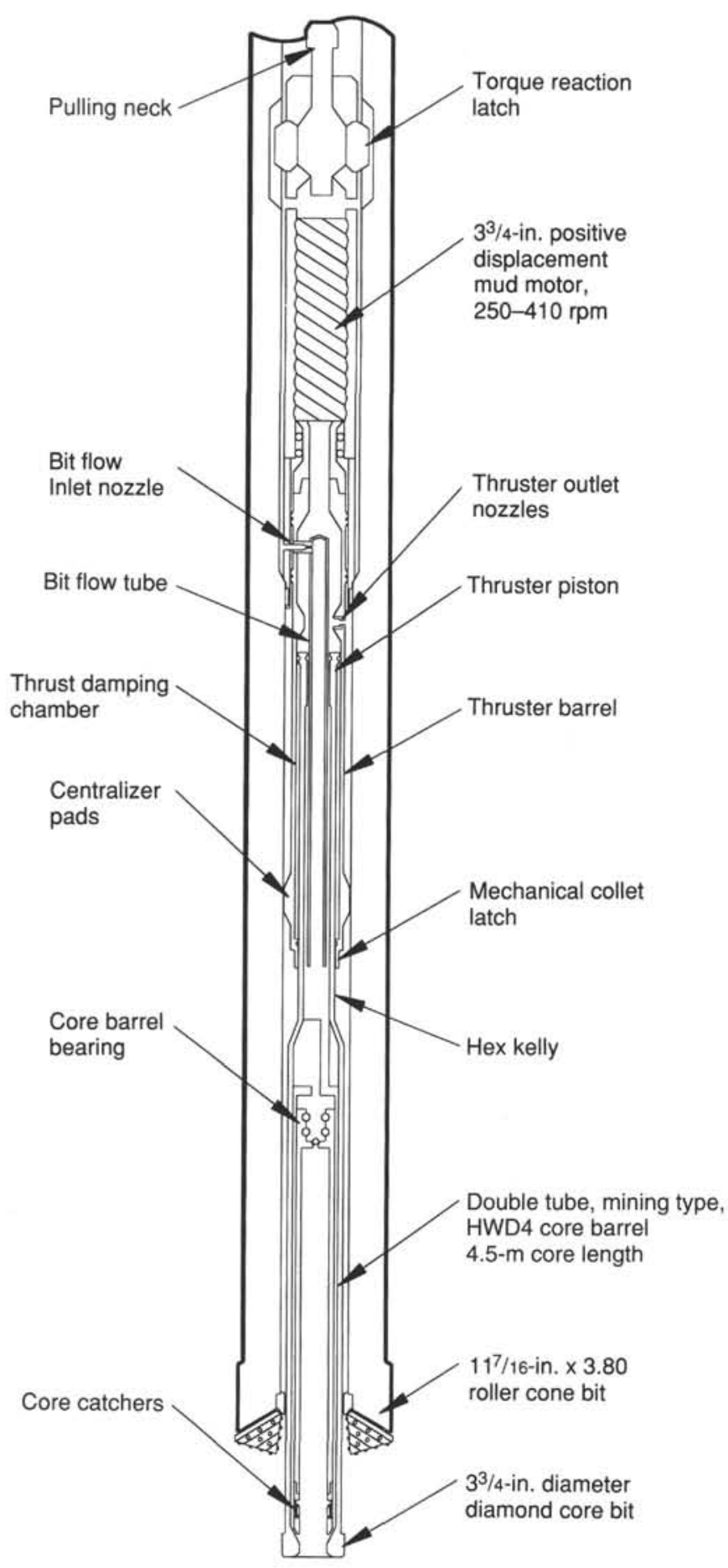

Figure 1. Schematic diagram of the 3.75 in. motor-driven core barrel (MDCB).

\section{Diamond Core Bits}

The MDCB is designed to operate with four different types of bits: three different narrow kerf diamond core bits and a tungsten carbide bit. All coring bits have an O.D. of $95 \mathrm{~mm}$ ( 3.75 in.) and cut a $57-\mathrm{mm}(2.25$-in.) core. The diamond bits available consist of both hard- and soft-matrix impregnated diamond as well as surface-set di- amonds and geoset (thermally stable diamond compact) bits. The tungsten carbide bits are for soft formations. Appropriate bit selection is determined by the type of formation to be cored. A surface-set diamond reaming shell is installed directly behind the core bit to enhance stabilization and help maintain hole gauge.

\section{LEG 158 RESULTS \\ Deck Test}

The MDCB was pulled out of the storage tubes and inspected before conducting a deck test to check the spaceout and operation of the tool. The tool was configured with one each 10/32-in. and 11/32-in. thruster nozzles and one each 3/32-in. and 4/32-in. bit nozzles. The $\mathrm{APC} / \mathrm{XCB} / \mathrm{MDCB} \mathrm{BHA}$ was assembled and the MDCB was placed in the seal bore drill collar (SBDC). The main bit was lowered down onto a 12 -in. $\times 12$-in. wooden tie to give the MDCB bit something to core against.

At 500 psi, the colleted latch released and allowed the MDCB bit to scope out onto the tie. Only about 1000 psi of pressure was allowed to build up because the purpose of the deck test was simply to test the latch and verify that the motor worked properly. The tool appeared to be functioning properly and was removed from the BHA so that the assembly of the remainder of the BHA could be finished.

\section{Hole 957C}

Before deploying the MDCB in Hole 957C, two half-core XCB cores were taken to increase the chance of core recovery with the MDCB and to penetrate at least 9 mbsf of sediment, which would provide a minor amount of stabilization to both the BHA and the MDCB. Cores $158-957 \mathrm{C}-1 \mathrm{X}$ and $-2 \mathrm{X}$ were zero recovery cores. The $\mathrm{XCB}$ core catchers had some pyrite and sulfide sand on them, indicating that the sulfides were breaking up and not getting into the core barrel. Ten MDCB cores were subsequently taken down to 49.2 mbsf, with recovery averaging around $64 \%$. Most of the material recovered was a breccia of varying amounts of pyrite, anhydrite, and silica. Also, chalcopyrite and sphalerite were recovered in the pyrite breccia. Anhydrite veins up to $45 \mathrm{~cm}$ thick were also present throughout the recovered sections. Figure 2 provides a breakdown of the general formation types encountered in each MDCB core recovered during Leg 158 . Individual $\mathrm{MDCB}$ runs produced outstanding sections of core compared to previous $\mathrm{XCB}$ or $\mathrm{RCB}$ attempts.

\section{Hole 957F}

The MDCB provided excellent core recovery in the interval from 20 to 50 mbsf in Hole $957 \mathrm{C}$. After scientific analysis of the cores from this interval, strong interest remained in attempting to drill MDCB cores in the interval from 0 to $20 \mathrm{mbsf}$. Because the seas were very calm, the decision was made to spud Hole $957 \mathrm{~F}$ from the seafloor with the MDCB and then continue down for $20 \mathrm{~m}$. Two MDCB cores were taken from 0 to $10 \mathrm{mbsf}$, for a total recovery of only 0.95 m. After taking Core $158-957 \mathrm{~F}-2 \mathrm{~N}$, the MDCB core barrel became stuck and the BHA had to be lifted to free the barrel. This resulted in the bit pulling free of the seafloor, which ended Hole 957F. The recovered core consisted of massive granular pyrite-chalcopyrite and nodular pyrite-anhydrite breccia (see Fig. 2).

\section{Hole 957G}

Hole 957G was to be drilled down to a depth of $10 \mathrm{mbsf}$, which was as far as Hole $957 \mathrm{~F}$ had advanced, and then coring was to be initiated. Three MDCB cores were taken down to 25.5 mbsf. Recovery was only $8 \%$ and consisted of massive, porous pyrite and massive pyrite-anhydrite breccia (see Fig. 2). The core samples lacked the ce- 


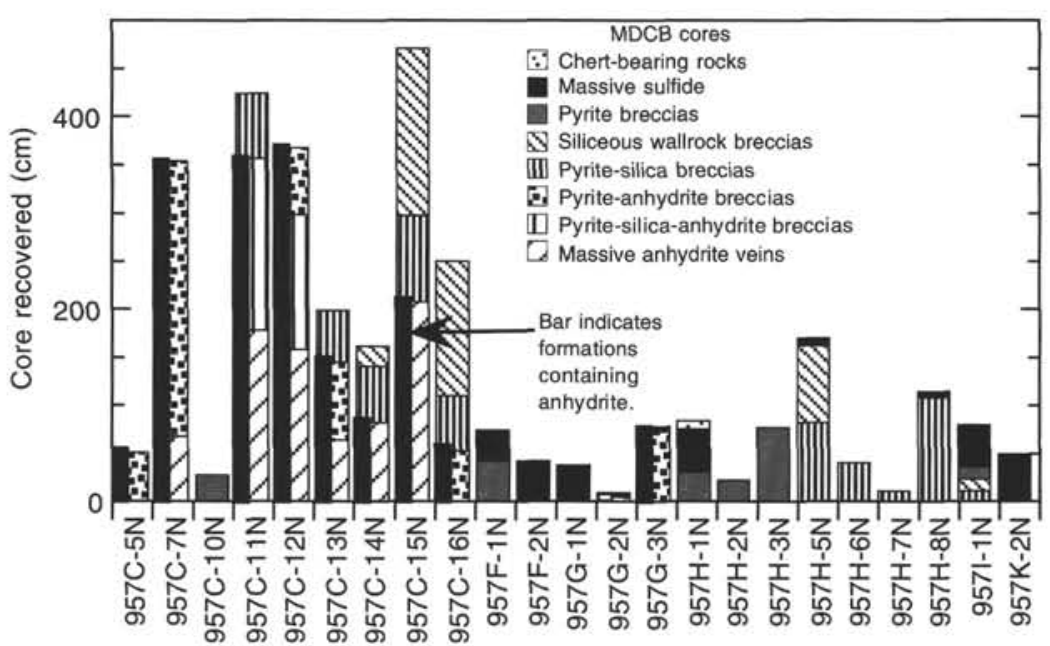

Figure 2. General formation types encountered in each $\mathrm{MDCB}$ core recovered during Leg 158 at Site 957. The formation types that contain some amount of anhydrite are highlighted by a vertical black bar. Note the distinct positive correlation between total core recovered and the amount of anhydrite in each core. mentation provided by the anhydrite in the Hole $957 \mathrm{C}$ and were also much more porous. These contrasts in the formation characteristics seemed to lower the overall ability to recover the heavy pyrite. During Core $158-957 \mathrm{G}-3 \mathrm{~N}$, the drill pipe became stuck and required high torque and overpull to free it. The hole was terminated after this point.

\section{Hole 957H}

The MDCB was used for eight cores from 8.7 to $44.7 \mathrm{mbsf}$ in Hole $957 \mathrm{H}$ in an attempt to recover the near-surface part of the hydrothermal mound in the white smoker area. Average recovery was $11 \%$ and consisted of porous massive pyrite with small anhydrite veins and minor amounts of chert in the upper part of the hole (see Fig. 2). The underlying section was comprised of pyrite-silica breccia with a narrow zone of silicified basalt breccia. Recovery may have suffered in this interval because of the high porosity of the rock as well as the lack of cementation.

\section{Hole 957I}

Only one MDCB core was taken at Hole 957I. Core 158-957I-1N was taken from 9.0 to $13.5 \mathrm{mbsf}$ and recovered $0.77 \mathrm{~m}$ or $17.1 \%$. Recovery consisted of porous massive pyrite containing significant amounts of marcasite and minor sphalerite (see Fig. 2). Hole 957I was terminated after the center bit following Core 158-9571-1N was retrieved and found to be missing the $\mathrm{XCB}$ shoe.

\section{Hole 957K}

One MDCB core was also taken at Hole 957K. Core 158-957KIN was taken from 9.0 to 13.5 mbsf and recovered $0.40 \mathrm{~m}$ or $9.0 \%$. Recovery consisted of massive pyrite with minor amounts of sphalerite and amorphous silica (see Fig. 2). Hole $957 \mathrm{~K}$ was terminated after Core $158-957 \mathrm{~K}-3 \mathrm{X}$ was retrieved and found to be totally destroyed as a result of main bit wear.

\section{MDCB Bit Performance at TAG}

Four different types of MDCB bits were used during Leg 158: three different diamond matrix bits (impregnated, geoset, and surface set) and one tungsten carbide model. The impregnated diamond bits are a general purpose bit that the mining industry uses for every formation from hard rock to shale to loose rubble. The impregnated matrix works by wearing away the soft matrix material and continuously exposing new diamonds to the formation. A piloted, face-discharge version of the impregnated bits was used with very good success at
TAG. The piloted version is meant for hard/soft interbeds as they will not break into the soft material all at once. The piloted impregnated bits (IMPP) averaged $49.7 \%$ core recovery, whereas the medium-formation, sawtooth cutting structure (IMPM) and the hard-formation, sawtooth cutting structure (IMPH) averaged $12.1 \%$ and $2.0 \%$, respectively (see Table 1 and Fig. 3).

The geoset bits are thermally stable diamond compacts (TSD) and look like little triangular pyramids set in the crown. This is a very aggressive bit that is designed for hard rock, soft rock, broken rock, or conglomerate. Because the TSD stand so far off the bottom of the hole, there is room for significantly greater circulating fluid flow to the bit. The geoset bits averaged $39.7 \%$ recovery for the leg.

The surface set bits contain small rounded diamonds set exposed from the crown material. These bits are designed for softer, unbroken rock (e.g., limestone), especially nonabrasive material that would have trouble wearing away the matrix on a impregnated bit. Surfaceset bits are more vulnerable to shock and overheating than are impregnated bits, but they resist balling if a sticky formation is encountered. All of the surface set bits run during Leg 158 were piloted with face discharge (SSP). The surface-set bits averaged $41.5 \%$ recovery for the leg.

\section{CONCLUDING REMARKS}

Many variable operating parameters can be set on the MDCB for each coring run. These parameters include bit selection, bit flow, motor thrust, and WOB. Any one of these parameters can have an effect on the core recovery depending on the type of formation encountered. Any time the MDCB is deployed, it may take several coring runs before the optimum parameter selection is achieved. Once the correct parameters are set, the MDCB is capable of excellent coring results.

The MDCB produced the highest core recovery percentage of any coring system during Leg 158 . Table 2 provides a comparison of core recovery for all of the various coring systems used.

As evidenced by the core recovery differences from various sites, the MDCB, like most coring systems, is extremely formation dependent. The distinct positive correlation between total recovery and the amount of anhydrite in cores from the TAG hydrothermal mound (see Fig. 2) is the most encouraging result of this operation. Some formations are more conducive to high-speed diamond coring, and, in some cases, this may be the only coring technique that will produce good core recovery, as appeared to be the case in the sulfides and sulfide breccias cored during Leg 158.

\section{Ms 158IR-104}


Table 1. MDCB recovery for various bit types during Leg 158.

\begin{tabular}{|c|c|c|c|c|c|c|}
\hline Core & IMPH & IMPM & GEOS & IMPP & SSP & TCS \\
\hline $\begin{array}{l}\text { Hole } 957 \mathrm{C} \\
3 \mathrm{~N} \\
5 \mathrm{~N} \\
7 \mathrm{~N} \\
9 \mathrm{~N}^{*} \\
10 \mathrm{~N} \\
11 \mathrm{~N} \\
12 \mathrm{~N} \\
13 \mathrm{~N} \\
14 \mathrm{~N} \\
15 \mathrm{~N} \\
16 \mathrm{~N} \\
\text { Runs } \\
\text { Ave. rec. } \\
\end{array}$ & 0 & $\begin{array}{l}1 \\
0.0\end{array}$ & $\begin{array}{c}107 \\
87 \\
2 \\
97.0 \\
\end{array}$ & $\begin{array}{c}11 \\
80 \\
1 \% \\
8 \\
90 \\
85 \\
56 \\
\\
\\
6 \\
55.0 \\
\end{array}$ & $\begin{array}{c}78 \\
\\
1 \\
78.0 \\
\end{array}$ & 0 \\
\hline $\begin{array}{l}\text { Hole } 957 \mathrm{~F} \\
\text { IN } \\
2 \mathrm{~N} \\
\text { Runs } \\
\text { Ave, rec. }\end{array}$ & & & $\begin{array}{c}18 \\
3 \\
2 \\
10.5 \\
\end{array}$ & & & \\
\hline $\begin{array}{l}\text { Hole 957G } \\
\text { IN } \\
2 \mathrm{~N} \\
3 \mathrm{~N} \\
\text { Runs } \\
\text { Ave. rec. }\end{array}$ & $\begin{array}{l}2 \\
1 \\
2.0 \\
\end{array}$ & & & $\begin{array}{r}18 \\
1\end{array}$ & $\begin{array}{l}5 \\
\\
1 \\
5.0 \\
\end{array}$ & \\
\hline $\begin{array}{l}\text { Hole } 957 \mathrm{H} \\
\text { IN } \\
2 \mathrm{~N} \\
3 \mathrm{~N} \\
4 \mathrm{~N} \\
5 \mathrm{~N} \\
6 \mathrm{~N} \\
7 \mathrm{~N} \\
8 \mathrm{~N} \\
\text { Runs } \\
\text { Ave, rec. }\end{array}$ & 0 & $\begin{array}{c}14 \\
\\
0 \\
35 \\
9 \\
2 \\
25 \\
6 \\
14.2\end{array}$ & 11.5 & 0 & 0 & 0 \\
\hline $\begin{array}{l}\text { Hole } 9571 \\
\text { IN } \\
\text { Runs } \\
\text { Ave. rec. }\end{array}$ & & & & & & $\begin{array}{c}17 \\
1 \\
17.0 \\
\end{array}$ \\
\hline $\begin{array}{l}\text { Hole } 957 \mathrm{~K} \\
\text { IN } \\
\text { Runs } \\
\text { Ave. rec. }\end{array}$ & 0 & 0 & 0 & 0 & 0 & $\begin{array}{l}9 \\
1 \\
9.0 \\
\end{array}$ \\
\hline $\begin{array}{l}\text { Total runs } \\
\text { Total ave. rec. }\end{array}$ & $\begin{array}{l}1 \\
2.0\end{array}$ & $\begin{array}{c}7 \\
12.1\end{array}$ & $\begin{array}{c}6 \\
39.7\end{array}$ & $\begin{array}{c}7 \\
49.7\end{array}$ & 21.5 & $\begin{array}{c}2 \\
13.0\end{array}$ \\
\hline
\end{tabular}

Notes: Asterisk $\left(^{*}\right)$ indicates that Core $158-957 \mathrm{C}-9 \mathrm{~N}$ (misrun) was not included in totals. Legend for diamond bits as follows: $\mathrm{IMPH}=$ impregnated, hard, sawtooth: IMPM = impregnated, medium, sawtooth: GEOS = geoset; IMPP = impregnated, hard, piloted; SSP = surface set, hard, piloted; and TCS = tungsten carbide, soft.
Table 2. Coring summary, Leg 158.

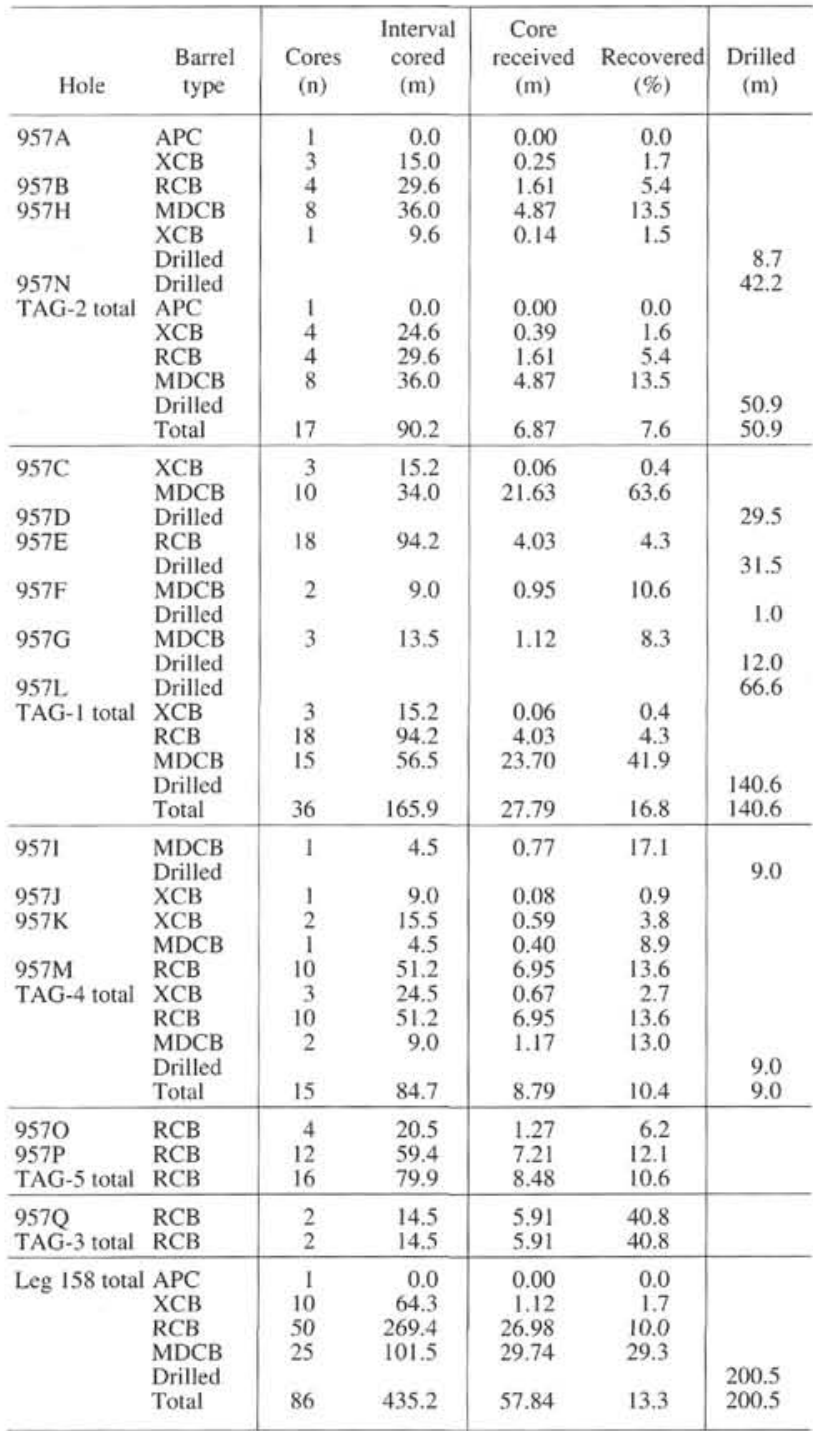



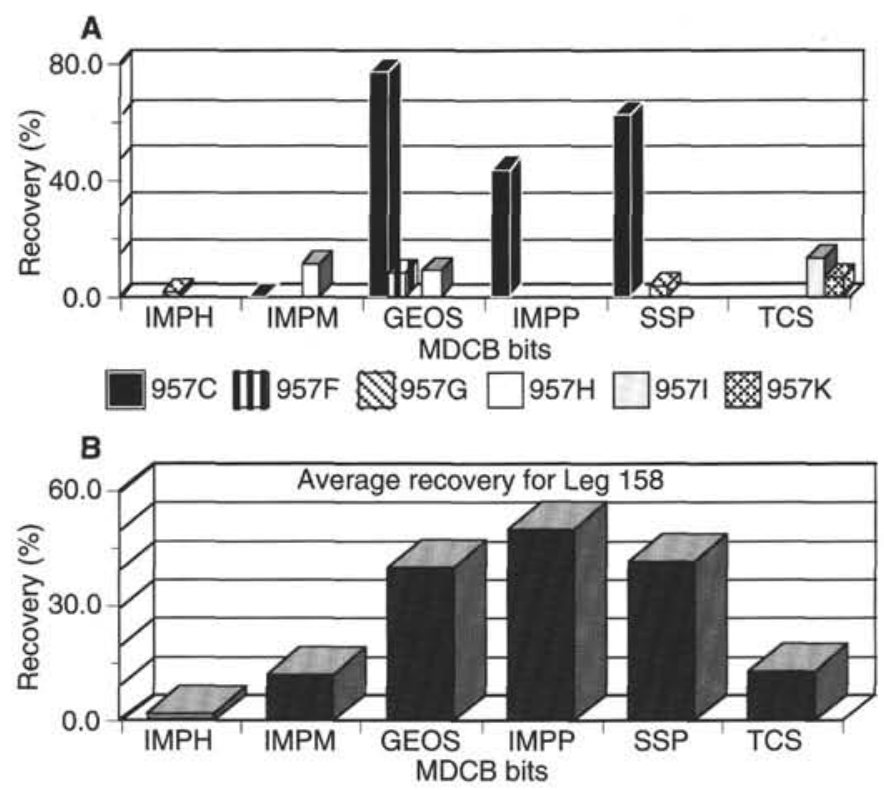

Figure 3. A. Average recovery by site for MDCB cores plotted relative to holes drilled and bit type. B. Average recovery for MDCB cores for Leg 158 plotted relative to bit type. $1 \mathrm{MPH}=$ impregnated, hard, sawtooth; IMPM = impregnated, medium, sawtooth; GEOS = geoset; IMPP = impregnated, hard, piloted; SSP = surface set, hard, piloted; and TCS = tungsten carbide, soft. 